\title{
Content validation of the Self-perception of Family Health Status scale using the Delphi technique
}

\author{
Joaquín Salvador Lima-Rodríguez ${ }^{1}$ \\ Marta Lima-Serrano ${ }^{2}$ \\ Nerea Jiménez-Picón ${ }^{3}$ \\ Isabel Domínguez-Sánchez ${ }^{4}$
}

Objective: To ascertain the content validity of the Self-perception of Family Health Status scale. Method: A validation study of an instrument with an online Delphi panel using the consensus technique. Eighteen experts in the subject were intentionally selected, with a multidisciplinary origin and representing different professional fields. Each of the proposed items was assessed using a five-point scale, and open-ended questions, to modify or propose items. Descriptive analysis was performed of the sample and the items, applying criteria of validation/elimination. Results: The first round had a response rate of $83.3 \%$ and validated 75 of the 96 proposed items; the second had a response rate of $80 \%$, and validated the 21 newly created items, concluding the panel of experts. Conclusions: We present an instrument to measure self-perception of family health status, from a nursing perspective. This may be an advance in scientific knowledge, to facilitate the assessment of the state of health of the family unit, enabling detection of alterations, and to facilitate interventions to prevent consequences to the family unit and its members. It can be used in clinical care, research or teaching.

Descriptors: Scales; Validation Studies; Family; Family Health; Delphi.

\footnotetext{
${ }^{1}$ PhD, Full Professor, Facultad de Enfermería, Fisioterapia y Podología, Universidad de Sevilla, Sevilla, Spain.

2 RN, Assitant Professor, Facultad de Enfermería, Fisioterapia y Podología, Universidad de Sevilla, Sevilla, Spain.

${ }^{3}$ MSc, Assistant Researcher, Facultad de Enfermería, Fisioterapia y Podología, Universidad de Sevilla, Sevilla, Spain.

${ }^{4}$ RN, Assistant Researcher, Facultad de Enfermería, Fisioterapia y Podología, Universidad de Sevilla, Sevilla, Spain.
}

\footnotetext{
Corresponding Author:

Marta Lima Serrano

Universidad de Sevilla. Departamento de Enfermería

Av. Sánchez Pizjuan, s/n

CEP: 41009, Sevilla, España

E-mail: mlima@us.es
} 


\section{Introduction}

The family is considered to be the principal nucleus of socialization of its members. It is the place where values are transmitted, where ideas are learned and adopted, and beliefs and norms of conduct are acquired. Its members are grouped into subsystems separated by symbolic boundaries, each contributing to family functioning through an exercise of roles and tasks necessary for the whole(1).

With the development of systems theory, adapted to living systems, the concept of family nursing has been defined as nursing care delivered to any system or household(2). It is necessary to be present and in intimate contact with the family, to discover ways that can fortify, mobilize, and propel it to achieve balance and well-being, going beyond the biological aspect of its members ${ }^{(3)}$. Nurses need to conduct research to recognize the needs of families, sources of support and social networks available to promote the health of its members $^{(4)}$.

All of this requires a change in clinical practice, to move from an individual to a group approach, including the social context in which the family group is immersed. To achieve this change, it is necessary to have a conceptual basis, an explanatory model, and an organization capable of implementing this process(5).

At present, several theorists have participated in different concepts of family and nursing care of the family(6), which is necessary to assume the challenge of developing the concept of family health and its dimensions, from a nursing perspective that allows its valuing.

For the World Health Organization (WHO), family health describes its function as a unit of structure, in relation to the family as the primary social agent, to promote health and well-being. This is related to satisfying the needs of its members, the interactions between the individual, the family and society, the solution to problems, or the ability to adapt to crisis situations.

Family health builds on the internal dynamics of the family, in decision making, in the education and socialization of its members, and in the availability and access to resources necessary for meeting its needs ${ }^{(7)}$. It is not static, it is a continuous and dynamic process that is undergoing continuous equilibrium and change, in response to events characteristic of the life cycle and those accidental events or situations that affect them.

Family health is intimately related to the family environment, the integrity of its members, the organization and operation of the unit, the capacity for resilience when faced with problems affecting it, and ways to address those problems ${ }^{(6)}$.

One of the difficulties in determining family health status is due to limitations that exist in the delimitation of the concept and the lack of consensus as to which indicators are needed to measure it, creating conceptual and methodological difficulties at the time of its evaluation. The Nursing Outcomes Classification (NOC) contains a set of indicators that can provide utility for overcoming these difficulties. The family health domain and family well-being class, contain the outcomes that describe the state of family health and social competence of the family as a unit in the overall family environment, including indicators of coping with family problems, family support during treatment, social climate of the family, health status of the family, family functioning, family integrity, standardization of the family, family participation in health care, and professional and family resistance(8). $^{(8)}$

From a systemic perspective of the family and a nursing approach that takes the NOC as its reference, Lima Rodriguez and colleagues, in their study of the dimensions of family health, proposed a rating system of family health which contemplated, along with the demographic aspects, the composition, structure, family life cycle and stress agents that may be impacting the family(6). They considered that these were: the family climate, family integrity, the function of family dynamics, family resistance, and family coping. Furthermore, when there was a family member with special needs or who required professional assistance, it was necessary to add family support, family normalization, and family participation in the care process.

To operationalize this proposal it is necessary to develop a series of instruments that, together with interviews and observation, enable the gathering of data necessary to evaluate the health of the family. Although some instruments exist that are applicable to the study of the family, for example the Family Apgar to evaluate family dynamics, the MOS questionnaire for social support, the Social Readjustment Scale for stressful life agents $^{(9-12)}$, several authors emphasize the urgent need for efforts to develop and validate new measurement instruments $^{(12-13)}$, adapted to the objectives of the discipline that needs them.

This article presents the design and content validation of an instrument intended to assess selfperception of family health status, inspired by the criteria of the Nursing Outcome Classification. This can 
present an advance in nursing knowledge, to allow us to identify family health situations that may require nursing interventions to improve or prevent the consequences they may have on the family system and also on its members, as in the family that may have an economic risk factors for its members ${ }^{(1,14)}$.

\section{Method}

The study was conducted in two phases: design of the scale and validation of its content.

\section{Phase I. Scale design}

This was performed in two stages: a) literature review, b) brainstorming and consensus of a small group of health professionals, teachers, managers and researchers, related to the care of the family, for item selection and preparation of the scale.

\section{1) Definition of dimensions and attributes}

Following previous authors, the NOC outcome criteria were used as a reference framework for designing the scale(15). We drew from outcome criteria proposed for the family health domain and the family wellbeing class, such as the family climate, family integrity, family functioning, family resistance, and family coping. In addition, for families in which one of its members has impaired health or necessitates health care, family support, family normalization, and family participation in the care process were added.

A literature review was conducted to identify the dimensions of family health and the instruments used to measure it from the user perspective. The search was conducted in PubMed, SCOPUS, Cuiden Plus; the keywords used in Spanish and English were health, family, assessment or evaluation, scales, indices, test. Articles were included with any methodology (quantitative, qualitative) and whose objective was clearly related to the research problem, or that made reference to aspects of interest for the work. We reviewed the bibliographies of the located articles.

\section{2) Selection of items and developing the scale}

The research group, through brainstorming and consensus, adopted a set of items, which were classified according to the dimension of family health to which they referred ${ }^{(9-12,16)}$. Subsequently, items were designed specifically for those attributes not represented, and the first version of the scale was constructed (Figure 1).

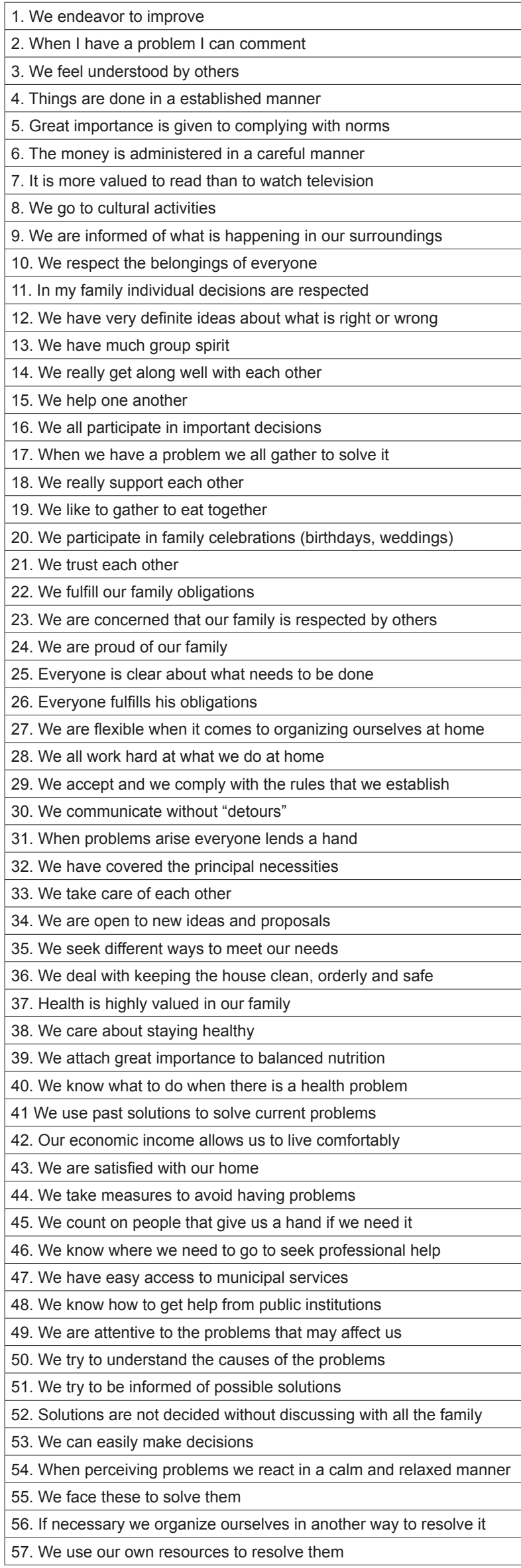

(The Figure 1 continue in the next page...) 


\begin{tabular}{|c|}
\hline 58. We help the rest of the family \\
\hline 59. We go to a professional if the problem requires it \\
\hline 60. When there are problems we try to regain normalcy \\
\hline 61. We care about their status \\
\hline 62. We take care to meet their needs \\
\hline 63. We help with those tasks they are unable to perform \\
\hline 64. We encourage them to do their part and improve their health \\
\hline 65. We try to understand their situation \\
\hline 66. We try to listen and communicate with him \\
\hline 67. We try not to remain isolated \\
\hline 68. We help with following the medical treatment \\
\hline 69. We report on his status to the rest of the family \\
\hline 70. We all collaborate in his care \\
\hline 71. We can agree about the care \\
\hline 72. We ask help of other people in the family \\
\hline 73. We recognize the particular needs of the sick \\
\hline 74. We try to live the situation as normally as possible \\
\hline 75. We encourage you to be as independent as possible \\
\hline 76. We organize ourselves to meet their needs \\
\hline 77. We replaced him in family obligations for which he can not comply \\
\hline 78. We aim to be best possible \\
\hline 79. We adapt the house to his needs \\
\hline 80. We go to associations of people with the same problem \\
\hline 81. We are living the illness or situation with normalcy \\
\hline 82. We see how it can affect the rest of the family \\
\hline 83. We try to help other affected family members \\
\hline 84. We endeavor to ensure that the family returns to normal function \\
\hline 85. We accompanied him during it \\
\hline 86. We offer the professional the information that is needed \\
\hline 87. We ask professionals to inform us of his status \\
\hline 88. We actively collaborate with professionals \\
\hline 89. We participate in decisions about what is to be done \\
\hline 90. We make decisions if the infirm person can not \\
\hline 91. We value it if attention is paid in an appropriate manner \\
\hline 92. If we are not in agreement we consult another professional \\
\hline 93. We try to get the resources needed \\
\hline 94. We organize ourselves to help when needed \\
\hline 95. We ensure that the patient has what is needed \\
\hline 96. If we do not agree with the professional we tell him \\
\hline
\end{tabular}

Figure 1 - Initial scale items sent to experts

In order to measure responses a Likert scale was chosen, because it allows a subject to respond, giving a degree of intensity to the statement of the item. Regarding the number of items necessary as a starting point, there is no rule, but obviously a higher the number of items will make it easier to make a good final selection ${ }^{(17)}$.

\section{Phase II. Validation of the scale content}

\section{Type of Design}

We conducted a validation study of an instrument through the use of an on-line Delphi panel, with expert judges, with a consensus technique. This technique attempts to obtain consensus of expert opinions on a subject through a series of structured questionnaires, referred to as phases. The responses to each questionnaire are considered for subsequent reformulation(18). This method allowed the purification and refinement of the initial scale.

Study Population

Through purposive sampling, 18 experts were selected. Given the difficulty of characterizing the sample, and to define the criteria for inclusion in validation studies, due to the lack of consensus on these ${ }^{(19)}$, we chose to have experts of a multidisciplinary origin (nurses, physicians and psychologists) belonging to different professional fields (healthcare, manager, teacher, researcher). To determine their inclusion, their knowledge and professional experience in relation to the topic of the instrument under validation were previously evaluated.

Procedure

Employing the web application "e-survey", information about the study objectives and the notions and theoretical considerations adopted for each of the dimensions of the scale was sent to participants. They were invited to participate voluntarily, ensuring the confidentiality and privacy of their input. After consent, the instrument was sent with instructions for completion. The study was approved by the Committee on Research Ethics of the Universidad de Sevilla, which reported favorably on the fulfillment of the requirements for human experimentation.

The degree of adequacy of each item must be established, according to a score of 1 to 5 ( $1=$ minor adequacy, 5 = higher adequacy). Initially 96 items were proposed, grouped into eight subscales, in functions of the dimensions considered family health. They were also offered the opportunity to suggest new items or propose amendments to those proposed.

Following the analysis of the data obtained in each round, the items were validated and eliminated according to the criteria: Validate: Mean $\geq 3.5$ and Median $\geq 3$ and high ratings (4-5) $\geq 80 \%$ and / or standard deviation $\leq 0.90$. Eliminated: Mean $<3.5$ and Median <3. The eliminated items were reviewed and modified according to proposals obtained, and moved through to the next round(20).

After each round, as a measure of feedback, a report was sent to each expert describing the item analysis, results obtained, and items validated, eliminated, or that should be assessed again.

Demographic variables were collected, to characterize the sample of experts: age, gender, place of residence, level of schooling and area of professional dedication. 
Data analysis

A descriptive analysis of the sociodemographic and study variables was conducted, supported by SPSS 18.0.

\section{Results}

\section{Phase I. Questionnaire design}

The scale was constructed to measure selfperception of family health status, initially consisting of 96 items grouped into eight subscales, one for each dimension of family health. These were: family environment, family integrity, family functioning, family resistence, family coping, family support, family normalization, and family involvement in the care process. For each dimension, 12 items were established. Three possible answers were identified: almost never $(A N)$, at times (AT), almost always (AA).

\section{Phase 2 Validation of the content of the scale}

The questionnaire was administered to 18 experts, and it took a total of two rounds to reach the necessary level of consensus.
There was an initial response rate of $83.3 \%$ (15 experts), and $80 \%$ (12 experts) in the second round. The mean age was 48 years, standard deviation of $10.7,77.8 \%$ were female $(n=14)$ and $22.2 \%$ male $(n=4), 88.8 \%$ of participants were from Seville $(n=16)$, $5.6 \%(n=1)$ from Mexico, and 5.6\% $(n=1)$ from Israel. Regarding the level of education, $33.4 \%$ were university graduates $(n=6), 39 \%$ had completed a master's degree $(n=7)$, and $27.6 \%$ had a doctoral degree (PhD) $(n=5)$; $50.0 \%$ were dedicated to teaching and research $(n=9)$, $44.4 \%$ to clinical practice $(n=8)$ and $5.6 \%(n=1)$ to management.

It took a total of two rounds to reach the necessary level of consensus. In the first, 75 items were validated (78.1\%) and 21 items were eliminated $(21.9 \%)$. Taking into account the contributions of the experts, modifications were made and these 21 items were subjected to another round of assessment, which were finally validated in their entirety, closing the panel of experts for the content validation (Tables 1 to 4$)$.

Table 1 - Items validated for Family Social Environment and Family Integrity

\begin{tabular}{|c|c|c|c|c|}
\hline Items & Mean & Median & SD & $\%$ value $(4-5)$ \\
\hline \multicolumn{5}{|l|}{ Family Social Environment } \\
\hline \multicolumn{5}{|l|}{ In my family: } \\
\hline We endeavor to improve & 4.1 & 4 & 0.51 & 91.7 \\
\hline When I have a problem I can comment & 4.2 & 4 & 0.94 & 80.0 \\
\hline We feel understood by others & 4.2 & 4 & 0.68 & 86.6 \\
\hline Things are done in an established manner & 3.7 & 4 & 0.70 & 73.4 \\
\hline Great importance is given to complying with the norms & 3.7 & 4 & 0.81 & 60.0 \\
\hline The money is administered in a careful manner & 3.8 & 4 & 0.75 & 58.4 \\
\hline The pursuit of intellectual activities is valued & 3.8 & 4 & 0.87 & 66.7 \\
\hline We go to cultural activities & 3.8 & 4 & 0.87 & 66.7 \\
\hline We are informed of what is happening in our surroundings & 4.0 & 4 & 0.84 & 80.0 \\
\hline We respect the belongings of everyone & 4.3 & 4 & 0.62 & 93.3 \\
\hline In my family individual decisions are respected & 4.3 & 4 & 0.62 & 93.3 \\
\hline We have very definite ideas about what is right or wrong & 4.0 & 4 & 0.80 & 73.3 \\
\hline \multicolumn{5}{|l|}{ Family Integrity } \\
\hline We have much group spirit & 3.7 & 4 & 0.70 & 73.4 \\
\hline We really get along well with each other & 4.2 & 4 & 0.77 & 80.0 \\
\hline We help one other & 4.2 & 4 & 0.67 & 86.6 \\
\hline We all participate in important decisions & 4.5 & 5 & 0.51 & 100.0 \\
\hline When we have a problem we all gather to solve it & 4.2 & 4.5 & 0.87 & 75.0 \\
\hline We really support each other & 4.2 & 4 & 0.68 & 86.6 \\
\hline We like to gather to eat together & 4.1 & 4 & 0.80 & 73.3 \\
\hline We participate in family celebrations & 4.1 & 4 & 0.74 & 80.0 \\
\hline We trust each other & 4.5 & 5 & 0.74 & 86.7 \\
\hline We fulfill our family obligations & 4.1 & 4 & 0.79 & 73.3 \\
\hline We are concerned that our family is respected & 3.7 & 4 & 0.81 & 60.0 \\
\hline We are proud of our family & 4.4 & 5 & 0.73 & 86.6 \\
\hline
\end{tabular}


Table 2 - Estimated items for Family Functioning and Family Resistance

\begin{tabular}{|c|c|c|c|c|}
\hline Items & Mean & Median & SD & $\%$ Value $(4-5)$ \\
\hline \multicolumn{5}{|l|}{ Family Functioning } \\
\hline \multicolumn{5}{|l|}{ In my family: } \\
\hline Everyone is clear about what needs to be done & 4.1 & 4 & 0.91 & 80.0 \\
\hline Everyone fulfills his obligations & 4.3 & 4 & 0.62 & 93.3 \\
\hline We are flexible when it comes to organizing ourselves at home & 4.3 & 4 & 0.59 & 93.3 \\
\hline We work hard at what we do at home & 3.9 & 4 & 0.83 & 60.0 \\
\hline We accept and we comply with established rules & 4.1 & 4 & 0.74 & 80.0 \\
\hline We communicate without "detours" & 4.3 & 4 & 0.72 & 86.7 \\
\hline When problems arise everyone lends a hand & 4.6 & 5 & 0.50 & 100.0 \\
\hline We have covered the principal necessities & 4.3 & 4 & 0.65 & 91.7 \\
\hline We take care of each other & 4.6 & 5 & 0.51 & 100.0 \\
\hline We are open to new ideas and proposals & 4.5 & 5 & 0.52 & 100.0 \\
\hline We keep the house clean, orderly and safe & 3.9 & 4 & 0.79 & 83.4 \\
\hline We clearly know who has the authority & 3.9 & 4 & 0.83 & 62.0 \\
\hline \multicolumn{5}{|l|}{ Family Resistance } \\
\hline We value having healthy habits & 4.1 & 4 & 0.76 & 75.0 \\
\hline We care about staying healthy & 4.3 & 4 & 0.70 & 86.7 \\
\hline We attach great importance to a balanced nutrition & 4.4 & 4 & 0.72 & 86.7 \\
\hline We know what to do when we have a health problem & 4.4 & 4 & 0.63 & 93.4 \\
\hline To resolve current problems we count on previous experiences & 4.0 & 4 & 0.51 & 100.0 \\
\hline We consider our resources sufficient & 3.9 & 4 & 0.79 & 83.4 \\
\hline We are satisfied with our home & 4.1 & 4 & 0.67 & 83.3 \\
\hline We anticipate problems to prevent them & 4.2 & 4 & 0.72 & 83.3 \\
\hline We count on people that give us a hand if we need it & 4.3 & 5 & 0.90 & 86.6 \\
\hline We know where we need to go to seek professional help & 4.4 & 4 & 0.51 & 100.0 \\
\hline We know how to get help from public institutions. & 3.9 & 4 & 0.83 & 73.3 \\
\hline We know how to access municipal services & 3.8 & 4 & 0.83 & 73.0 \\
\hline
\end{tabular}

Table 3 - Items estimated for Family Coping, and Family Support

\begin{tabular}{|c|c|c|c|c|}
\hline Items & Mean & Median & SD & $\%$ Value $(4-5)$ \\
\hline \multicolumn{5}{|l|}{ Family Coping } \\
\hline \multicolumn{5}{|l|}{ In my family: } \\
\hline We are attentive to the problems that may affect us & 4.1 & 4 & 0.70 & 80.0 \\
\hline We try to understand the causes of the problems & 4.4 & 4 & 0.63 & 93.4 \\
\hline We try to be informed of possible solutions & 4.3 & 4 & 0.59 & 66.7 \\
\hline Solutions are not decided without discussing with all the family & 3.9 & 4 & 0.80 & 66.7 \\
\hline Shared decision making is not a problem & 4.0 & 4 & 0.74 & 75.0 \\
\hline We react to problems in a calm and relaxed manner & 4.1 & 4 & 0.74 & 80.0 \\
\hline We face problems to solve them & 4.0 & 4 & 1.13 & 83.3 \\
\hline If necessary we organize ourselves in another manner & 3.9 & 4 & 0.88 & 73.4 \\
\hline We use our own resources to resolve them & 3.7 & 4 & 0.81 & 60.0 \\
\hline We help the rest of the family & 4.0 & 4 & 0.74 & 75.0 \\
\hline We go to a professional if the problem requires it & 4.0 & 4 & 0.62 & 93.3 \\
\hline When there are problems we try to regain functioning & 4.2 & 4 & 0.58 & 91.7 \\
\hline \multicolumn{5}{|l|}{ Family support } \\
\hline \multicolumn{5}{|l|}{ In my family when someone is ill: } \\
\hline We care about their status & 4.0 & 4 & 0.85 & 66.6 \\
\hline We take care to meet their needs & 4.4 & 5 & 0.83 & 80.0 \\
\hline We help with those tasks they are unable to perform & 4.6 & 5 & 0.63 & 93.4 \\
\hline We encourage them to do their part and improve their health & 4.3 & 5 & 1.10 & 86.6 \\
\hline We try to understand their situation & 4.4 & 4 & 0.63 & 93.4 \\
\hline We try to listen and communicate with him & 4.3 & 4 & 0.62 & 93.3 \\
\hline We try not to remain isolated & 4.3 & 4 & 0.80 & 80.0 \\
\hline We help him follow the medical treatment & 4.3 & 4 & 0.70 & 86.7 \\
\hline
\end{tabular}


Table 3 - (continuation)

\begin{tabular}{|c|c|c|c|c|}
\hline Items & Mean & Median & SD & $\%$ Value (4-5) \\
\hline We report on his status to the rest of the family & 3.7 & 4 & 0.88 & 60.0 \\
\hline We all collaborate in his care & 4.3 & 4 & 0.80 & 80.0 \\
\hline We can agree about caring for him & 4.5 & 5 & 0.64 & 93.3 \\
\hline We ask help of other people in the family & 4.0 & 4 & 0.53 & 86.6 \\
\hline
\end{tabular}

Table 4 - Family standardization and family involvement in the care process

\begin{tabular}{|c|c|c|c|c|}
\hline Items & Mean & Median & SD & $\%$ Value (4-5) \\
\hline \multicolumn{5}{|l|}{ Family standardization } \\
\hline \multicolumn{5}{|l|}{ In my family when someone is ill: } \\
\hline We recognize the particular needs of the infirm person & 4.1 & 4 & 0.83 & 73.3 \\
\hline We encourage him to live the situation as well as possible & 4.1 & 4 & 0.74 & 80.0 \\
\hline We encourage him to be as independent as possible & 4.3 & 4 & 0.72 & 86.7 \\
\hline We get organized to do those tasks he cannot & 4.2 & 4 & 0.77 & 80.0 \\
\hline We aim to be best possible & 4.4 & 4 & 0.63 & 93.4 \\
\hline We adapt the house to his needs & 4.5 & 5 & 0.64 & 93.3 \\
\hline We go to associations of people with the same problem & 4.4 & 5 & 0.74 & 86.6 \\
\hline We integrate the care of his infirmity into our daily lives & 4.4 & 5 & 0.79 & 83.3 \\
\hline We see how it can affect the rest of the family & 4.1 & 4 & 0.88 & 80.0 \\
\hline We try to help other affected family members & 4.1 & 4 & 0.88 & 66.7 \\
\hline We ensure that the family functions with normalcy & 4.5 & 5 & 0.74 & 86.7 \\
\hline We replace him in the obligations that he can not manage & 3.75 & 4 & 0.89 & 75.0 \\
\hline \multicolumn{5}{|l|}{ Family involvement in the care process } \\
\hline \multicolumn{5}{|l|}{ In my family when someone receives health care: } \\
\hline We accompany him during this & 4.3 & 5 & 0.91 & 80.0 \\
\hline We offer the professional the information that he needs & 4.4 & 4 & 0.63 & 93.4 \\
\hline We ask professionals to inform us of his status & 4.5 & 5 & 0.74 & 86.7 \\
\hline We actively collaborate with professionals & 4.6 & 5 & 0.51 & 100.0 \\
\hline We participate in decisions about what is to be done & 4.2 & 4 & 1.08 & 86.7 \\
\hline We make decisions if the infirm person cannot do so & 4.6 & 5 & 0.63 & 93.4 \\
\hline We organize to help when needed & 4.1 & 4 & 0.83 & 73.3 \\
\hline We ensure that the patient has what he needs & 4.5 & 5 & 0.74 & 86.7 \\
\hline We try to get the resources needed & 4.3 & 5 & 0.81 & 80.0 \\
\hline We value it if care is provided adequately & 4.1 & 4 & 0.70 & 80.0 \\
\hline If we do not agree with the professional we tell him & 4.2 & 4 & 0.86 & 86.7 \\
\hline If we are not consulted we seek another professional & 4.3 & 4 & 0.80 & 80.0 \\
\hline
\end{tabular}

\section{Discussion}

Several authors agree on the need to design and validate new measurement instruments when no others exist that measure what we really intend to measure, as is the case of the scale presented here ${ }^{(12-13)}$.

Nursing outcome criteria describe the state, behaviors, reactions and feelings of the patient and, although they initially were developed to measure these responses to care administered(19), they can become evaluation criteria that allow us to determine status, in the case at hand, related to family health.

The Delphi technique is widely used for the validation of scales and questionnaires by expert opinion(12,20-23), making explicit criteria important for the selection thereof and ensuring that such experts are appropriate for the subject matter of the study to validate the instrument, thus avoiding bias $^{(24)}$. Other measures proposed to avoid bias are standardizing the definitions of each dimension of the scale, and its principal subcomponents, to make them available to the expert group to unify knowledge on the field of study and to be critical when evaluating and scoring the items, with positive repercussion on the validity of the instrument ${ }^{(25)}$.

The performance of the technique on-line promoted speed in completion and facilitated the opportunity for participation of international experts. Also, the sample size used in the validation process was consistent with the proposed number in previous studies to stabilize the responses of each of the items. A response rate 
of over ten members in the first round is considered suitable according to the recommended proposals for the application of the Delphi technique(24). Compliance with these aspects gives more power and strength to the validation process.

Quantitative values provided by the Delphi panel were very high. Furthermore, the introduction of a system that allowed experts to make qualitative contributions, through open responses, improved the validation process, as their proposals alluded to improved understanding of the items and the elimination or inclusion of new items ${ }^{(23-24)}$.

One limitation in the design of the instrument could be not having conducted focus groups or interviews with the population to obtain these items. However, to the extent that to construct a test should be clearly defined from the construct and its theoretical conceptualization and should find items that represent it, we conducted a comprehensive review of the literature and previously validated instruments were used for selection.

One limitation of the Delphi technique is that it does not generate a real consensus among experts, but forces them to choose, without any opportunity for discussion or analysis of each of the participants' ideas. In exchange, avoiding direct confrontation slows the induction of precipitous judgments and inhibition of new ideas, by helping with gradual formation of an opinion. Controlled feedback stimulates the generation of ideas and facilitates the removal of irrelevant information, and can be stimulating and productive for participants $^{(25)}$.

\section{Conclusions}

We present an instrument to measure SelfPerception of Family Health Status, which has demonstrated adequate content validity. This identifies eight dimensions for this theme, which can be studied independently. This instrument provides specific indicators to measure family health, and permits the identification of the perception that members have of the health of their family. This gives it a wide applicability in clinical practice, completing the necessary information to assess the family.

This scale can be useful for epidemiological studies and other types of research, in the field of management, planning, follow-up care, and the health care setting.

From the methodological point of view, to be based on outcome criteria, the data is easily combined with the proposed evaluation system and nursing taxonomies.
In future research it would be advisable to apply a pilot sample to analyze its psychometric properties, proving its reliability, construct and criterion validity.

\section{References}

1. Cid-Monckton $P$, Pedrão LJ. Factores familiares protectores $y$ de riesgo relacionados al consumo de drogas en adolescentes. Rev. Latino-Am. Enfermagem. 2011;19(Spe):738-45.

2. Rocha SM, Nascimento LC, Lima RA. Enfermagem pediátrica e abordagem da família: subsídios para o ensino de graduação. Rev. Latino-Am. Enfermagem. 2002;10(5):709-14.

3. Barbosa SM, Costa P, Vieria NF. Etapas de cambios de los padres en las conversaciones con los hijos sobre la prevención de HIV/SIDA. Rev. Latino-Am. Enfermagem. 2008;16(6):1019-24.

4. Paula ES, Nascimento LC, Rocha SM. The influence of social support on strengthening families of children with chronic renal failure. Rev. Latino-Am. Enfermagem. 2008;16(4):692-9.

5. Balón E, De la Revilla L. La atención familiar la asignatura pendiente. Atención Primaria. 2011;43(2):55-7.

6. Lima J, Lima M, Saéz A. Intervenciones enfermeras orientadas a la familia. Enferm Clín. 2009;19(5):280-3.

7. Mejías LD, López L. La familia y la cultura: una conexión innovadora para el cuidado de la salud. Index Enferm. 2010;19(2-3):138-42.

8. Moorhead S, Jonson M, Maas ML, Swanson E. Clasificación de Resultados de Enfermeria (NOC). $4^{a}$ ed. Barcelona: Elsevier; 2009.

9. Bellón JA, Delgado A, Luna JD, Lardelli P. Validez y fiabilidad del cuestionario de función familiar Apgarfamiliar. Atención Primaria. 1996;18(6):289-95.

10. De la Revilla L, Luna J, Bailón E, Medina I. Validación del cuestionario MOS de apoyo social en Atención Primaria. Med Familia. 2005;6(1):10-8.

11. González JL, Morera A. La valoración de sucesos vitales: Adaptación española de la escala de Holmes y Rahe. Psiquis. 1983;4(1):7-11.

12. Moraes CL. Reichenheim ME. Cross - cultural measurement equivalence of the Revised Conflict Tactics Scales. Portuguese version used to identify violence within couples. Cad Saúde Publica. 2002 [acesso 2 nov 2011]; 18:783-96. Disponivel em: http://www.scielosp. org/pdf/csp/v18n3/9306.pdf.

13. García DeYébenes MJ, Rodríguez F, Carmona L. Validación de cuestionarios. Reumatol Clín. 2009;5(4):171-7. 
14. Medina N, Ferrini, MG. Factores protectores de las familias para prevenir el consumo de drogas en un municipio de Colombia. Rev. Latino-Am. Enfermagem. 2010,18(Spe): 504.

15. Porcel AM, Villaverde C, Morales JM. Medida del nivel de dependencia en cuidados enfermeros. Preliminares de una propuesta metodológica. Scentia: Rev Multidisciplinar Cienc Salud. 2008(13):131-6.

16. Sandín B, Chorot P. Cuestionario de Afrontamiento al Estrés (CAE): Desarrollo y validación preliminar. Rev Psicol Psicopatol Clín. 2003;1(8):39-54.

17. Morales P. Medición de actitudes en psicología y educación. $3^{a}$ ed. Madrid: Universidad Pontificia de Comillas; 2008.

18. Perroca MG. Desarrollo y validación de contenido de la nueva versión de un instrumento para clasificación de pacientes. Rev. Latino-Am. Enfermagem. 2011,19(1):58-66.

19. Seganfredo DH, Almeida, MA. Validación de contenido de resultados de enfermería según la Clasificación de los Resultados de Enfermería (NOC) para pacientes clínicos, quirúrgicos y críticos. Rev. Latino-Am. Enfermagem. 2011;9(1):34-41.

20. Martínez-Piñeiro E. La Técnica Delphi como estrategia de consulta a los implicados en la evaluación de programas. Revista de investigación educativa. RIE. 2003;21(2):449-64.

21. Ballesteros-Pérez AM, Saturno $P$, Ortega $P$, Mínguez $\mathrm{R}$, Molina F, Martínez MT, et al. Construcción y validación de una escala de actitudes hacia la atención primaria de salud. Atención Primaria. 1996;18(4):168-75.

22. Carretero-Dios $H$, Pérez C. Standards for the development and review of instrumental studies. Int J Clin Health Psychol. 2007;7(3):863-82.

23. Hasson F, Keeney S, McKenna H. Research guidelines for the Delphi survey technique. J Adv Nurs. 2000;32(4):1008-15.

24. Argimón JM, Jiménez J. Métodos de investigación clínica y epidemiológica. Madrid: Harcourt; 2000.

25. Yañer R, Cuadra R. La técnica Delphi y la investigación en los servicios de salud. Cienc Enferm. 2008;14(1):9-15. 